\title{
Las clasificaciones ashaninka de la fauna del piedemonte central: un caso de diferentes niveles de aproximación
}

Les classifications ashaninka de la faune du piémont central : un exemple de différents niveaux d'approche

Ashaninka classification of central piemont fauna: an example of different levels of approach

\section{Enrique Rojas Zolezzi}

\section{OpenEdition}

Journals

Edición electrónica

URL: http://journals.openedition.org/bifea/6468

DOI: 10.4000/bifea.6468

ISSN: 2076-5827

Editor

Institut Français d'Études Andines

Edición impresa

Fecha de publicación: 1 abril 2003

Paginación: 185-212

ISSN: 0303-7495

\section{Referencia electrónica}

Enrique Rojas Zolezzi, «Las clasificaciones ashaninka de la fauna del piedemonte central: un caso de diferentes niveles de aproximación », Bulletin de l'Institut français d'études andines [En línea], 32 (1) I 2003, Publicado el 08 abril 2003, consultado el 07 diciembre 2020. URL : http:// journals.openedition.org/bifea/6468; DOI : https://doi.org/10.4000/bifea.6468

\section{(c) (†) $\odot$}

Les contenus du Bulletin de l'Institut français d'études andines sont mis à disposition selon les termes de la licence Creative Commons Attribution - Pas d'Utilisation Commerciale - Pas de Modification 4.0 International. 


\title{
LAS CLASIFICACIONES ASHANINKA DE LA FAUNA DEL PIEDEMONTE CENTRAL: UN CASO DE DIFERENTES NIVELES DE APROXIMACIÓN*
}

\author{
Enrique ROJAS ZOLEZZI**
}

\section{Resumen}

Partiendo de una crítica a la antropología y a la llamada etnociencia, el presente artículo muestra el caso de los ashaninka de la Amazonia central peruana, quienes han desarrollado diversos niveles de clasificación de los animales del bosque. Así, en este sistema sociocultural coexisten nomenclaturas de carácter prototípico junto a sistemas de clasificación estrechamente vinculados con el sistema cosmológico de esta sociedad.

Palabras claves: Etnociencia, sistema de clasificación, clasificación prototípica, relaciones analógicas, mitología.

\section{LES CLASSIFICATIONS ASHANINKA DE LA FAUNE DU PIÉMONT CENTRAL : UN EXEMPLE DE DIFFÉRENTS NIVEAUX D'APPROCHE}

\section{Résumé}

Cet article part de la critique de l'anthropologie et de l'ethnoscience, et montre que les Ashaninka de l'Amazonie centrale péruvienne ont développé divers niveaux de classification des animaux de la forêt. Ainsi, l'article montre la coexistence, dans le système socio culturel ashaninka de nomenclatures au caractère prototypique et de systèmes de classification, lesquels sont liés à la cosmologie de cette société.

Mots clés: Ethnoscience, système de classification, classification prototypique, relations analogiques, mythologie.

* El trabajo de campo en que se basa el presente artículo fue realizado gracias a fondos del Legado Lelong administrados por el CNRS y otorgados en 1998. La estadía en el terreno fue realizada en el marco del trabajo de promoción social y desarrollo ejecutado por el equipo de campo de la Asociación para la Conservación del Patrimonio del Cutivireni (ACPC), ONG nacional. A ambas entidades deseo expresar mi mayor agradecimiento. La redacción de este artículo ha sido posible gracias al apoyo brindado como investigador local por el Instituto Francés de Estudios Andinos (IFEA) durante el año 2000.

**A Av. Nicolás de Aranibar 635 Lima 1 Perú. E-mail: erojazol@ hotmail.com. 


\title{
ASHANINKA CLASSIFICATION OF CENTRAL PIEMONT FAUNA: AN EXAMPLE OF DIFFERENT LEVELS OF APPROACH
}

\begin{abstract}
based on a critique of anthropology and ethnoscience, this article shows that in the Ashaninka's case, there is a coexistence of different classification systems of forest's animals. This exposition shows that prototipical nomenclature coexists with other classification systems that bear a strong relation with Ashaninka's cosmology.
\end{abstract}

Key words: Ethnoscience, classification system, prototypical classification, analogical relations, mythology.

\section{INTRODUCCIÓN}

El presente artículo trata de un aspecto de las representaciones a partir de las cuales los ashaninka organizan sus relaciones con los seres vivientes del entorno en donde habitan, a saber, las taxonomías de la fauna del piedemonte oriental de los Andes centrales. Así, buscamos en este texto mostrar los esquemas de clasificación de mamíferos, aves, peces, batracios e insectos desarrollados por los ashaninka a partir de los cuales estos interactúan con los seres vivientes del entorno, esquemas construidos a partir de "la singular configuración de relaciones de diferencia y similitud entre lo existente, sus propiedades, sus disposiciones, sus acciones" (Descola, 2001: 21). Asimismo buscamos una aproximación al carácter atribuido por esta sociedad por medio de su mitología al campo de las relaciones entre los seres de cultura o personas y los seres de natura, en el caso de este artículo limitándonos a la fauna, representaciones que juegan un rol de gran importancia en la definición de las actividades que involucran la explotación de estos organismos, patrones de significación en la mente de los actores sociales de este grupo étnico que tienen la función de pautas para la acción o "esquemas de praxis" como los ha llamado Descola (1996: 87).

Los ashaninka constituyen un grupo de horticultores de roza, cazadores, pescadores y recolectores de la familia Arawak en su rama maipureana y se encuentran en la región de la cabecera del río Ucayali, que comprende los ríos Perené, Ene, Tambo, Pichis, Pachitea, Urubamba y la región interfluvial del Gran Pajonal. Así, el territorio tradicional de este grupo comprende un sector de la varcea del Ucayali, el piedemonte de los Andes y zonas de tierra firme interfluviales, siendo predominantemente colinoso.

Los datos que aquí presentamos fueron recogidos en las comunidades de Camantavishi y Cutivireni en la margen derecha del río Ene, zona del territorio tradicional ashaninka donde esta población aún sigue un modo de vida tradicional y donde la fauna todavía se encuentra bastante conservada (1), a diferencia de otras donde

(1) Para la identificación de los mamíferos grandes y medianos fueron empleadas ampliaciones fotográficas de las láminas en color del libro de Emmons (1997) sobre este tema en el bosque tropical sudamericano. Este mismo procedimiento fue empleado para la identificación de serpientes en base a ampliaciones de las fotografías presentadas en las monografías de Dixon \& Soini (1986), Duellman (1978), Peters \& Orejas Miranda (1970). Para el caso de las aves fueron empleadas igualmente ampliaciones fotográficas de las láminas presentadas por Hilty \& Brown (1986) complementadas con 
el bosque ha sufrido un grave deterioro efecto de la colonización y actividades extractivas como la de la industria forestal. Debemos señalar, sin embargo, que incluso en esta zona la ictiofauna puede encontrarse afectada debido al relave minero que hemos visto asentarse en las orillas del río Ene, el que desciende desde las minas de la sierra central por las aguas del río Mantaro. Dentro del territorio ashaninka se presentan hasta cuatro tipos de bosque diferentes de acuerdo a altitud, humedad y suelos, y los resultados aquí presentados se centran principalmente en el tipo de bosque que corresponde a la margen derecha del río Ene (bosque tropical seco, 500 m.s.n.m.) así como en las variantes dialectales de la lengua ashaninka en dicha zona.

\section{DIFERENTES NIVELES DEAPROXIMACIÓN EN UN MISMOSISTEMA}

La clasificación ashaninka de seres vivientes del bosque presenta, lo que podemos llamar, diferentes niveles de aproximación. Un primer nivel está constituido por categorías estrechamente vinculadas a la cosmología. En este nivel los taxones se encuentran relacionados con ciertas características de la cosmogonía de esta sociedad. A un segundo nivel con gran independencia de la cosmología encontramos una clasificación de acuerdo a los modos de locomoción y capacidad de atacar al hombre de los diferentes seres vivientes del entorno. A un tercer nivel encontramos que el conjunto de lexemas que funciona como taxas y taxones se reúnen en conjuntos organizados alrededor de un determinado taxón en un tipo de clasificación que Berlin ha denominado prototípico. Este presenta una gran independencia de la cosmología si bien debemos decir que todos los términos guardan una relación de coherencia con dicho sistema, en

aquellas presentadas por Fjeldsa \& Krabbe (1990). A fin de evitar cualquier confusión de parte de los informantes, se compararon los resultados así obtenidos con la lista de aves existentes en la zona presentada por Weske (1972). Para el caso de los peces, la identificación se basó en la recolección de especímenes de pequeño y mediano tamaño y el fotografiado de estos cuando sus dimensiones no hicieron posible su conservación. Los materiales resultantes fueron identificados por el profesor Daniel Ortega y el equipo del Departamento de Ictiología del Museo de Historia Natural de la UNMSM. Batracios, insectos y moluscos fueron colectados y los especímenes identificados respectivamente por Javier Icochea del Departamento de Herpetofauna del Museo de Historia Natural de la UNMSM, Clorinda Vergara del Museo de Entomología de la Universidad Nacional Agraria y los biólogos del Departamento de Malacología del Museo de Historia Natural de la UNMSM. Las identificaciones botánicas señaladas en el texto fueron realizadas por la bióloga Joaquina Albán del Museo de Historia Natural de la UNMSM. Respecto a los sistemas de clasificación, estos fueron trabajados con grupos de informantes alfabetizados compuestos por tres hombres y tres mujeres adultos por medio del método de tarjetas propuesto por Berlin. Una vez identificadas las especies por el grupo de seis informantes señalado tras un corto debate, ya sea presentándoles las láminas de color o especimenes dentro de envases, eran anotados los nombres de cada especie en tarjetas las que luego eran agrupadas. Preguntas como “ ¿cual es su familia?” “ “ cual es el dirigente de la familia?” sugeridas por Berlin mostraron ser eficaces para dar a entender a los informantes el tipo de información lingüística que queríamos de ellos. Se llegaba a un resultado luego de un nuevo debate entre los miembros del grupo de informantes. En el transcurso de la investigación, sin embargo resultó evidente que debíamos complementar dicha metodología con el acercamiento a otras formas de enunciado en la lengua vernácula cuando detectamos términos que engloban diferentes formas de vida en recitaciones mitológicas, términos que forman parte del sistema de clasificación. Así, ha formado parte de nuestro método la recolección de este tipo de discurso mediante entrevista, grabación y posterior traducción de la tradición oral del grupo estudiado. 
la medida en que constituye una aplicación, como veremos, de las categorías de la organización política de la sociedad al ámbito de los seres de la naturaleza.

En el primer nivel de clasificación señalado encontramos categorías referidas al mito de origen de la principal divinidad ashaninka, el sol, por medio de las cuales son separados los animales buenos para comer de los considerados dañinos. Esta categorización guarda relación también con otras dos concepciones que forman parte de este sistema. De una parte la idea, expresada en diferentes textos míticos, de que al inicio del mundo todos los seres vivientes dotados de movimiento eran seres de cultura o personas y que posteriormente perdieron esta característica al ser transformados en seres de natura tal como hoy se los conoce. Otra idea presente en la cosmología de este grupo relacionada con este nivel de clasificación presenta una concepción de la muerte según la cual se considera como un destino posible para los seres de cultura su transformación en seres de natura.

En una relación de mayor independencia de la cosmología la lengua ashaninka presenta en un segundo nivel una clasificación general de los animales construida a partir del criterio de las formas de locomoción. Para los ashaninka, las plantas constituyen, dentro de los seres vivientes, aquellos que se caracterizan por su inmovilidad; los animales, por el contrario, se definen por su capacidad de movimiento siendo este el criterio a partir del cual éstos son clasificados, como veremos.

En el tercer nivel encontramos un sistema de clasificación general de toda la fauna junto a un ordenamiento de los taxones referidos a mamíferos, aves, peces, insectos, que siguiendo a Berlin podemos considerar de carácter prototípico.

\section{LOS QUE ROMPEN HUESOS Y LOS BUENOS PARA COMER}

En el primer nivel señalado, encontramos que en el mito de origen del sol, en una versión registrada por nosotros, la mujer madre del sol fecundada por Luna, al momento de dar a luz $-\mathrm{y}$ al sufrir un gran dolor- escupe los diferentes tipos de animales, estableciéndose en dicho texto mítico la categoría de "animales que rompen huesos" (ikaharantayete). Los "animales que rompen huesos" tal como están señalados en el mito son en primer lugar animales e insectos considerados dañinos, como las serpientes en general que atacan a los hombres, y los zancudos y mosquitos portadores de enfermedades. Asimismo, se incluyen en esta categoría a mamíferos tales como el venado maniro (el rojo Mazama americana y el gris Mazama gouazoubira) y el añuje sharoni (Dasyprocta variegata) a los que se les atribuye una naturaleza malevolente en la cosmología. Así, el venado, de acuerdo al mito ashaninka, es un cazador fracasado, que al no poder obtener presas ofrece a sus parientes la propia carne de sus muslos, la que hacía luego crecer mágicamente. Descubierto al fin, es perseguido por los parientes que habían sido, bajo engaño, inducidos a una conducta caníbal —uno de los actos más reprobables moralmente para los ashaninka - huye al bosque y se transforma en el animal de largas y delgadas patas que hoy vemos. Respecto al añuje sharoni, los ashaninka consideran que los shamanes que han cometido en vida incesto se transforman al morir en dichos animales, con lo cual le atribuyen una naturaleza malevolente (Elick, 1969: 225). 
Los "animales que rompen huesos" (ikaharantayete) presentan una relación de contraste en este sistema con los animales poshineri, "los buenos para comer". Esta constituiría una primera clasificación ligada a concepciones cosmológicas y que pauta los patrones de consumo de la caza entre los ashaninka. Así, si los animales poshineri son en toda circunstancia buenos para comer, los clasificados en la categoría de "los que rompen huesos" no son considerados seres totalmente puros, en alguna medida malevolentes y no pueden servir de alimento durante la enfermedad de una persona, ni durante las etapas críticas de desarrollo de éstos (momento del parto, crisis de pubertad) a riesgo de producir enfermedades o agravarlas.

Tenemos así una categorización general de la fauna que, como podemos ver, define prohibiciones alimentarias. Esta organización se encuentra ligada a una concepción que adscribe a ciertas especies una capacidad de transformación interespecífica y considera esta como un destino posible para los seres humanos tras la muerte.

La concepción de transformación interespecífica señalada se encuentra ligada a otro tipo de restricción alimentaria, aquella que prohibe el consumo de mamíferos de todas las especies considerados dentro de la categoría de peyari. Esta categoría es utilizada, como ha señalado Weiss (1975), por los cazadores ashaninka cuando obtienen una presa que presenta signos de enfermedad o es muy vieja. Esta entonces, es tratada como peyari, abandonada y no considerada apta para la alimentación. Sin embargo es también utilizada para designar una presa sospechada de constituir un difunto transformado en mamífero dentro de esta concepción de transformación interespecífica.

La categoría de peyari presenta una expresión verbal en la forma del sufijo clasificador -niro que podemos traducir como "silvestre, salvaje, peligroso". Todos los mamíferos considerados supuestos peyari presentan el taxón correspondiente a la especie seguido del sufijo clasificador -niro lo que indicaría que son peyari, y por lo tanto peligrosos para alimentarse. Algunos ejemplos nos permitirán ilustrar esta característica del sistema. El camarón de río en la lengua ashaninka recibe el taxón kito y los escorpiones reciben el taxón de kitoniro, considerándose el último la versión silvestre y peligrosa del primero dentro de una misma taxa. En la mitología ashaninka, se dice que antiguamente el escorpión, así como la avispa y la hormiga eran hombres guerreros quienes fueron transformados por el demiurgo Awíreri en los seres que hoy vemos con un aguijón por haberse puesto las flechas y los arcos a la espalda, cosa que los ashaninka nunca hacen. Cabe aquí hacer notar en relación al significado de este sufijo el caso del término para designar al venado, maniro compuesto por este sufijo. Esto guardaría relación con el mito anteriormente presentado, según el cual un ser de cultura - el cazador - es transformado en un ser de natura por su conducta antisocial. La carne de venado se encuentra excluida de la alimentación de personas enfermas o atravesando períodos críticos. Esto nos lleva a analizar la relación que este sufijo guarda también con la concepción sobre el destino de los muertos. En este sistema de ideas se considera que existen diferentes destinos posibles para un difunto, y uno de ellos puede ser el de su transformación en un ser de natura o animal. Se dice que cuando un muerto persiste en mantenerse cerca de sus parientes vivos sin tomar el rumbo hacia la tierra de los muertos, entonces terminará por transformarse en lo que se denomina un peyari, lo que puede ser definido como una persona que por algún motivo no llegó a ingresar a la tierra de los 
muertos, transformándose en ese caso en un animal en la tierra de los hombres y mujeres vivos. Se considera que toda especie animal tiene su peyari y este no puede ser comido por los familiares del difunto. Así, los ashaninka pueden hablar de manironiro para referirse a un venado maniro que sospechan sea un peyari, es decir, un difunto reciente que se ha transformado. Cuando en un asentamiento a los pocos días del deceso de un miembro de la comunidad, es cazado, en las cercanías de las habitaciones de los familiares del difunto, un mamífero o un ave que presenta la característica de ser un animal ya viejo, se piensa que la presa es el peyari del difunto, siendo entonces descartado para la alimentación. En el sistema, sin embargo, estos animales transitarían más allá del lugar de residencia de los parientes del difunto, pudiendo ser cazados por ashaninka no parientes en las zonas de caza de otras comunidades, confundiéndose con las otras presas de la misma especie de animal, sirviendo entonces de alimento para otros ashaninka.

Encontramos una creencia similar para el caso de los peces aunque no esté marcado el léxico como en el caso de los mamíferos. Los ashaninka consideran que los grandes peces de aguas profundas llamados zúngaros o saltones (Pimelodidae), en especial el iyochi (Pseudoplatystoma fasciatum) son personas muertas cuyos cadáveres arrojados a los ríos se han transformado en estas especies. Es creencia entre los ashaninka que durante la enfermedad o etapas críticas del desarrollo del indivíduo, este debe abstenerse de comer estos peces, pudiendo alimentarse de peces de aguas superficiales.

Debemos subrayar que además del llamado peyari los ashaninka atribuyen en su mitología a cada especie de mamífero terrestre un ashitarori o dueño, en ocasiones también llamado padre o iriri, y a los peces un padre para todos denominado kiatsi o nihaweri. Los iriri son seres mitológicos que crían a los mamíferos en el interior de grandes cavernas en los cerros desde donde los envían a los hombres para ser cazados (Elick, 1969). El dueño de los animales por excelencia, según nuestros informantes vendría a ser el que cuida de los piratsi (Tayassu peccari) ya que este es uno de los pocos mamíferos que se desplaza en grupos numerosos a la manera de un hato. Con excepción del jaguar maniti (Panthera onca) quien se considera posee un alma análoga a la de los hombres en tanto que shaman transformado y guardián de las buenas costumbres en la sociedad de los hombres o seres de cultura, en este sistema no se les atribuye un alma a los animales o seres de natura. Así la figura del dueño o padre de los animales, muy extendida en las bajas tierras de América del Sur, suerte de hipóstasis de la especie animal a la que es asociado, como bien ha señalado Viveiros de Castro "atribuye con una intencionalidad análoga a la de los humanos" a los animales "creando un campo intersubjetivo para las relaciones humano-animal" (Viveiros de Castro, 1998: 471). En el caso ashaninka la relación establecida entre seres de natura y seres de cultura a través de la figura del dueño o padre de una especie es la de la donación de presas de caza a estos últimos. Así, desde sus habitaciones en lo alto de los cerros los míticos dueños o padres de los diferentes mamíferos envían a sus hijos (los animales) para que sean cazados por los hombres.

Una relación análoga es establecida entre kiatsi o niháweri, los peces y los hombres. Los peces son enviados por este ser para que sean atrapados por los hombres. 
Casos especiales de esta relación son aquellos en los que determinadas especies de mamíferos o aves - y no seres míticos - son considerados los dueños de ciertas especies. Los ashaninka establecen una relación entre diferentes recursos animales y vegetales y ciertas especies de aves a los cuales se les atribuye la función de portadores y donadores de aquellos. En estos casos los ashaninka han incorporado al modelo establecido de relación entre un ser mítico donador y una especie donada a situaciones en que se ha establecido una correlación entre la inmigración o presencia numerosa de una especie en el territorio ashaninka y el arribo o la presencia numerosa de determinada especie animal. Así, como ya ha señalado Weiss, al colibrí tsonkiri a la manera de un mensajero de las divinidades se le atribuye el traer a los hombres la planta del tabaco y se atribuye a la golondrina etsoni ser la portadora de las larvas comestibles a los hombres (Weiss, 1975). Vale la pena señalar que el tabaco aparece espontáneamente según los ashaninka en los suelos despejados de maleza alrededor de las casas, en la mitad del verano, cuando la presencia de los colibries es numerosa. De manera análoga la golondrina ashiwanti (Chaetura sp.) es considerada dueña de las orugas y escarabajos comestibles porque los ashaninka han establecido una correlación entre la llegada o inmigración de estas aves a su territorio y la aparición numerosa de estas orugas y escarabajos comestibles hacia la misma época en el centro de la estación lluviosa. Las golondrinas al llegar se alimentan de estos insectos para sobrevivir pero los ashaninka dicen que estas aves traen a dichos insectos. La presencia numerosa de las larvas comestibles a mediados de la estación lluviosa coincide con la llegada de las golondrinas. Una relación similar es atribuida a la nutria parari (Mustela africana) y al martín pescador tserepito (no identificado) respecto a los peces. Los ashaninka dicen que el martín pescador tserepito que arriva en el centro de la estación seca, coincidiendo con la mijanada, es el portador de los pequeños peces clasificados en la etnocategoría shiwa. Ellos anuncian la llegada de los peces mayores en dicha estación, los que serían traídos por el lobo de agua parari. La mijanada de los peces en agosto corresponde a una época del año en que estos dos animales pescadores — normalmente cautelosos ante la presencia humana - son entonces a menudo observados por los ashaninka quienes en ese mismo mes pescan en el río. Los ashaninka dicen entonces que la nutria ha venido desde río abajo trayendo a los peces (Weiss, 1975: 259) atribuyéndole a esta especie un patrón migratorio análogo al de la golondrina así como un rol donador similar. Respecto al martín pescador señalan también que trae los peces en esa época aunque no se le atribuye un patrón migratorio. De este modo, una relación de predación observada por los ashaninka en base a la presencia paralela de estas especies es incorporada al modelo de relación de donación entre un ser mítico, una especie animal y los hombres. Las especies en cuestión, sin embargo, no son consideradas divinidades. Se trataría por el contrario de mensajeros de divinidades mayores. Así la golondrina etsoni se dice anida en las nubes donde habitan los manínkari suerte de divinidades ancestrales a quienes sirve y a la nutria parari se le atribuye ser hija de Pachákama quien habita al final del río.

Ciertos comportamientos que se considera comprometen la existencia de los recursos de caza como por ejemplo herir torpemente sin llegar a atrapar las presas o cazar más allá de lo necesario son consideradas conductas ante las que el dueño o padre de los animales retirará a sus hijos del bosque. Asimismo es necesario señalar que en la mitología ashaninka la figura del peyari no sólo atribuye una transformación tras la 
muerte a los seres de cultura en seres de natura, sino que otorga a algunos de estos la capacidad de cambiar su forma de animal y presentarse en forma de personas para atacar a los cazadores y pescadores si es que estos cazan o pescan más allá de lo necesario para satisfacer sus necesidades y las de su entorno social. Así, si un cazador atrapa demasiados mamíferos terrestres o aves, poniendo en peligro el equilibrio entre los grupos de animales y el conjunto de las personas corresidentes en una determinada zona dentro del territorio ashaninka, éste será atacado en el bosque por un peyari en forma de persona con el que luchará, lo que le producirá una enfermedad en ocasiones mortal. En el caso de los mamíferos terrestres los peyari constituyen seres distintos de los dueños o padres de los animales si bien como en el caso de éstos se atribuye uno a cada especie de mamífero. Se atribuye sin embargo a ciertos peyari la función de ayudantes de los dueños de los animales en el cuidado de las presas. En el caso de los peces, es el propio kiatsi o niháweri quien se dice ataca a los pescadores que atrapan demasiados peces, poniendo en peligro la existencia del recurso en una zona. Asimismo se le atribuye la capacidad de presentarse en forma humana por lo que este ser es considerado un peyari.

Finalmente, algunas especies de insectos como las hormigas y ciertas especies de abejas que viven son considerados matsi, es decir, brujos. En la mitología ashaninka las personas consideradas brujos o matsi ocasionan enfermedades a otras personas de su comunidad a través de la manipulación de restos corporales o residuos de los alimentos tomados por sus víctimas. Los ashaninka establecen así una analogía entre la figura de los humanos matsi y las hormigas las que observan tomar partes de los residuos de los alimentos preparados o abejas de las que se dice toman gotas de transpiración de los cabellos humanos y sangre y pequeños trozos de carne de las presas de caza (Weiss, 1975: 296).

Los que "rompen huesos" ikaharantayete, los llamados peyari y los matsi constituyen todos sub-categorías de una categoría mayor que comprende todos los seres malevolentes del cosmos ashaninka que reciben la denominación de kamari, término que puede ser traducido como "lo que mata". Esta categoría se opone a otra la de maninkari o amachenka de la que forman parte los donadores "dueños de los animales".

En conclusión, en un primer nivel de clasificación ligado a los mitos cosmogónicos en el que ocupa un lugar importante la noción de transformación interespecífica encontramos una oposición entre dos categorías ikaharantayete- poshiniri y el sufijo clasificador -niro los que definen restricciones alimenticias a las personas respecto a ciertas especies animales en este sistema. Asimismo, a los seres de natura o animales se les atribuye un dueño o padre, figura mítica a partir de la cual se atribuye al espacio entre los hombres y los seres de natura un determinado modo de relación, a saber, el de donación. En este espacio sin embargo son definidas en base a dicha figura mítica reglas que pautan el grado de punción de los recursos de caza y pesca siendo atribuida también a cada especie un peyari, suerte de ser transformista que alterna la forma humana con la del animal y que puede atacar al infractor que comprometa con sus acciones la existencia continua de los seres de natura.

\section{1. Clasificación de los animales según su modo de locomoción y capacidad para morder}

En un segundo nivel de clasificación los ashaninka ordenan a los seres de natura dotados de movimiento a partir de dos criterios fundamentales, a saber, el modo de 
locomoción y si pican o muerden o no. A partir de estos criterios definen las siguientes categorías:

a) anítachiri: los que caminan sobre la tierra con patas, categoría que incluye a los mamíferos terrestres. Al interior de esta categoría los jaguares son clasificados en maniti (jaguar) si no muerden a las personas y en kashékari si han atacado y devorado personas;

b) kamatsatáchiri: todos los que se desplazan arrastrando la panza, categoría que incluye a todos los reptiles sean estos serpientes (maranke), lagartijas de tierra, lagartos, tortugas terrestres y caracoles;

c) achikantáchiri: los kamatsatáchiri que muerden, categoría derivada de la anterior y que comprende todas las serpientes que muerden, sean estas venenosas o no;

d) amatsekáchiri: todos los que se desplazan saltando sobre el suelo, categoría que comprende los sapos;

e) mitaháchiri: los que se desplazan saltando por árboles y arbustos, categoría que comprende los mamíferos arbóreos, ciertos sapos, saltamontes, lagartijas arbóreas, grillos y langostas;

f) wankinti: los que vuelan con alas, categoría que comprende aves y mariposas. Esta categoría sin embargo excluye los murciélagos que pertenecen a otra categoría como luego veremos;

g) timáhatirori: los que se desplazan por el agua, categoría que incluye todos los peces grandes y pequeños como también caracoles de agua, tortugas acuáticas, cangrejos, camarones chinches acuáticos, gusanos acuáticos;

h) itsáranka: los que tienen alas sin plumas, categoría que comprende por una parte a los murciélagos pihiri y por otro a la raya inaro. Esta categoría se define por el término dado a las alas del murciélago el que es aplicado por los ashaninka también para designar las partes laterales del cuerpo de la raya acuática;

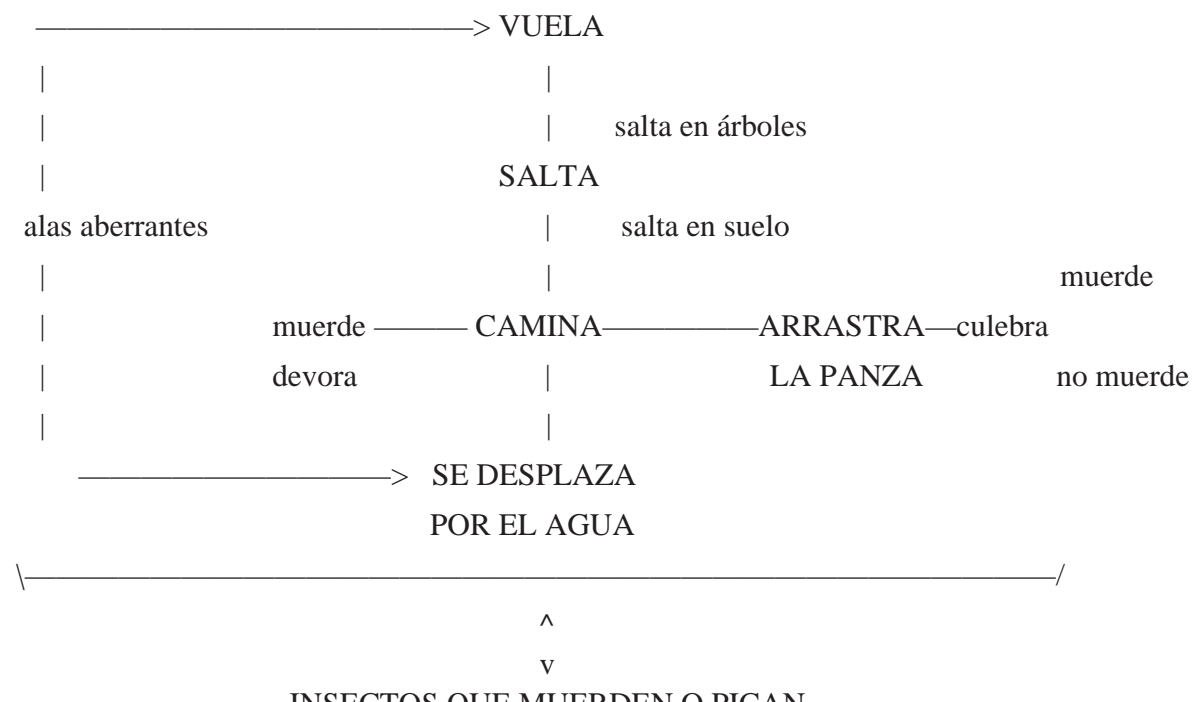

INSECTOS QUE MUERDEN O PICAN 
i) owantáchiri: los que pican, categoría que incluye los insectos con aguijón y pinzas tales como avispas, abejas, arañas y hormigas.

Este sistema de categorías puede ser resumido en el siguiente esquema:

Una categoría que forma parte de este sistema de clasificación y que ha jugado un papel muy importante en la incorporación conceptual de la mayor parte de los animales introducidos desde fuera es la categoría de wirantsi; puede ser traducida como "los animales que caminan por la casa" por oposición a aquellos ubicados en el ámbito silvestre del bosque. Originalmente utilizada para designar a los pichones de tucanes, loros y panguanas, así como a las crías de tapir capturadas y criadas en el espacio alrededor de la casa, hasta el momento en que eran utilizadas para la alimentación, esta categoría ha servido para designar luego a la gallina tyapa, el pato patyo y a los carneros y cerdos introducidos por misioneros y los programas públicos y privados de desarrollo.

Esta clasificación, debemos subrayar, se encuentra enmarcada dentro del sistema de clasificación según el cual se encuentran "animales buenos para comer" y los que son potencialmente peligrosos para la alimentación o "animales que rompen huesos".

$\mathrm{Al}$ interior de estas categorías los ashaninka agrupan mamíferos, aves y peces en familias cada una con un dirigente siguiendo el modelo de clasificación prototípica estudiado por Brent Berlin (1992) como mostraremos a continuación.

\section{CLASIFICACIÓN SEGÚN MODELO PROTOTÍPICO}

En un último nivel de clasificación, los ashaninka clasifican las diferentes especies distinguidas por la nomenclatura científica occidental siguiendo un modelo que ha sido denominado por Berlin como prototípico. Así, los ashaninka reúnen alrededor de una especie que consideran la más perfecta al conjunto de las especies que, dadas sus características morfológicas, aparecen como similares. Un ejemplo de esto lo encontramos en la clasificación ashaninka de palomas. Las palomas son agrupadas alrededor de la especie definida como prototípica que en este caso es la llamada sampakitsi (Columba Cayennensis) estando el grupo constituido por otras especies de palomas como potooti (Columba speciosa), pamoro (Columba fasciata), kontsaro (Leptotila verreauxi y Leptotila rufaxila), tookiti (Claravis pretiosa y Claravis mondetoura) y pochoñeihi (Geotrygon montana). Siguiendo este modelo de clasificación los ashaninka llaman a la especie prototípica jefe o dirigente y al resto de las especies reunidas en un conjunto llamado los parientes del jefe. De esta manera organizan al conjunto de los animales en un modelo conceptual análogo a aquel por el cual es organizada la sociedad de los seres de cultura o seres humanos. Los ashaninka viven en asentamientos liderados por un individuo denominado pinkatsari, suerte de dirigente local, constituyendo los coresidentes generalmente un grupo de consanguíneos y afines. Este modelo es trasladado al mundo natural para denominar pinkatsari a la especie prototípica de un grupo de especies animales agrupadas por sus características similares, siendo denominados ashaninka o parientes a las especies que son ubicadas alrededor de la señalada especie prototípica. De esta manera, el mundo natural es ordenado siguiendo el modelo del mundo social. Las diferencias y similitudes entre los seres de natura son aprehendidas así a partir del modelo de la vida social. 
Debemos subrayar que la especie considerada prototípica en cada grupo es un ser tangible y por lo tanto algo totalmente distinto al personaje mítico del llamado "dueño" o "padre" de los animales que ya hemos analizado.

El modelo de clasificación ashaninka de mamíferos, aves, peces, batracios, reptiles, moluscos e insectos según el modelo prototípico es presentado en extenso en el apéndice 1 del presente artículo. Señalamos aquí las características más saltantes de dicho modelo.

En algunos casos como el de los mamíferos, los batracios y las abejas una especie específica es considerada la prototípica o dirigente de todo el conjunto. Este es el caso del tapir (Tapirus terrestris) para los mamíferos, el sapo mashero (Bufo Marinus) para los batracios y la abeja nerontoki (Apis mielifera) para las abejas. En los dos primeros casos se trata de las especies de mayor tamaño y en la última la que presenta el rasgo distintivo de productora de miel de manera más acusada. En algunos casos una característica morfológica como el tamaño constituye un criterio de clasificación importante. Así, entre las aves y los peces las especies más pequeñas son reunidas en una única gran categoría. Los pequeños peces son reunidos en la categoría de shiwá y las pequeñas aves en la categoría de tsimeri. Entre los batracios las diferentes especies son reunidas en dos familias, una compuesta por los más grandes y otra por los más pequeños. La semejanza morfológica y el tamaño no constituyen sin embargo los únicos criterios de clasificación de las especies existiendo otros referidos al comportamiento animal como el tipo de habitat (terrestre o arbóreo), las horas de vigilia y la peligrosidad. Así entre los mamíferos, los ashaninka reúnen en una sola familia a las especies nocturnas que viven en los árboles. De esta manera son reunidos en una familia liderada por el kinkajú kitsani (Potos flavus) la chozna mochori (Bassaricyon sp.), la zariguella kapaheri (Delphis marsupialis) llamada también sari, el mono musmuqui pitoni (aotus sp.) el puerco espín tontori (Coendou bicolor), la laucha chiowante (Marmosa murina) y la rata de bambú tarato (Dactylomys dactylinus). En este sistema taxonómico, la rata de bambú tarato, a pesar de su similitud morfológica con el ratón onkicha y el conejo de monte kima (Sylvilagus brasiliensis) no es clasificado con éstos porque mientras caminan por el suelo, el otro vive trepado en el bambú y árboles pequeños y porque mientras éstos son diurnos la rata de bambú tarato es nocturna. Otro caso similar es el de la familia liderada por el perezoso soroni (Choloepus hoffmanni) y constituida por el oso hormiguero wantana (Tamandua tetradactyla) y el oso hormiguero shani (Myrmecophaga tridactyla), especies reunidas según los criterios: viven en los árboles y poseen grandes uñas y cola prensil. Por su parte los ofidios son agrupados en cuatro familias definidas según el criterio de grado de peligrosidad. Así una primera familia está constituida por aquellas especies que no poseen veneno y no pican; la segunda por las que no tienen veneno pero pican cuando se las molesta; la tercera por aquellas que tienen veneno pero pican sólo cuando se las molesta; la cuarta y última familia por aquellas agresivas (con o sin veneno) que atacan al hombre sin que se las moleste ( $c f$. apéndice 1).

Las "relaciones de familia" reconocidas por los ashaninka entre especies de mamíferos, aves, batracios, serpientes, peces e insectos no llegan sin embargo a involucrar a la totalidad de la fauna de la región donde habitan, dándose entonces en este sistema de clasificación el caso de los "solitarios" o "sin familia", individuos tan distintos a los otros en su morfología que no han sido incorporados a los conjuntos 
construidos en base al criterio de la similitud que rige este nivel de clasificación. En general, se trata de especies cuyas características morfológicas los hacen a tal punto distintos que difícilmente pueden ser agrupados con otros. De la misma manera que en la sociedad ashaninka existen individuos huérfanos que han perdido a toda su familia a causa de guerras y epidemias, por analogía, existen en este sistema de clasificación individuos solitarios que vendrían a ser estas especies de morfología distinta. Entre los mamíferos, este es el caso del oso de anteojos maini (Tremarctos ornatus). Entre las aves el gran solitario es el paujil thamiri o tsamiri (Crax mitu) el que, como en el caso del oso entre los mamíferos, dadas sus características morfológicas distintas a las otras aves de la región, no ha sido incorporada a los conjuntos de aves organizados según el criterio de la similitud. Entre los peces el pez aguja pityochichówaki (Pseudotylosurus microps) por su particular morfología es considerado un solitario. En el caso del oso de anteojos su morfología distinta a la de todas las otras especies es explicada por la mitología a través de los caracteres míticos que les son atribuidos. El oso maini es considerado nieto del monstruo mitológico llamado por los ashaninka Korinto, descrito como un gran cuadrúpedo caníbal provisto de una gran trompa con la que atrapaba a los hombres. Estos monstruos antropófagos fueron encerrados en cavernas por los shamanes ashaninka para hacer posible la vida de los hombres.

Asimismo en la sociedad ashaninka existen los llamados matzi, suerte de individuos excluidos socialmente por sospechosos de practicar la brujería. De manera análoga, se atribuye a ciertas especies la práctica de la brujería por lo que son consideradas excluidas de todo grupo o "familia". Tal es el caso de ciertas especies de abejas. De esta manera diferentes formas de asociación y exclusión en la vida social de los hombres son usadas como modelo para ordenar mentalmente el ámbito de los seres de la naturaleza.

\section{CONCLUSIONES}

De los datos etnográficos expuestos, lo primero que encontramos es que los ashaninka presentan una pluralidad de conjuntos de categorías utilizadas para la clasificación de los animales que corresponden a niveles taxonómicos distintos. Así, encontramos en un primer nivel un sistema categorial ligado a las concepciones cosmogónicas que define una serie de prohibiciones alimenticias respecto a la fauna; en un segundo nivel encontramos un sistema categorial que partiendo de la oposición móvil-inmóvil en relación con los vegetales clasifica a los animales según su modo de desplazamiento y su capacidad para agredir a los hombres; en un tercer nivel encontramos un modo de clasificación que pone el énfasis en el reconocimiento de las discontinuidades en el mundo natural, que agrupa a los seres de la naturaleza según sus semejanzas morfológicas si bien como hemos visto de carácter prototípico, criterio distinto al modelo linneano occidental. Estos diferentes niveles de clasificación guardan una relación de coherencia entre sí y son aplicados en diferentes circunstancias de la vida cotidiana de los ashaninka.

Como podemos ver, para entender cómo los ashaninka clasifican los animales no podemos limitarnos a la nomenclatura a la manera de los estudios propuestos por Berlin. Como podemos constatar en este caso, la nomenclatura guarda relación con toda una 
mitología implícita necesaria para entender las asociaciones establecidas entre los seres vivientes de la naturaleza. Queda claro hasta aquí que los animales no son meros objetos en dicha concepción y que en alguna medida son entendidos como sujetos sociales. De hecho, como hemos visto, los ashaninka organizan a los seres naturales en familias cuyos miembros se encuentran agrupados alrededor de un líder o dirigente constituido por la especie prototípica. Al lado de esta especie prototípica aparece también en este sistema la figura mitológica del "padre" o "dueño" de la especie para el caso de mamíferos y la figura de kiatsi o "dueño de los peces" para el caso de estos últimos. Todo ello nos muestra, pues, el carácter social atribuido por los ashaninka al conjunto de los animales con los que interaccionan en sus actividades productivas cotidianas. De esta manera los ashaninka proyectan el modelo de organización de su sociedad a su entorno natural.

De la misma manera que en la sociedad ashaninka pueden darse huérfanos y gente sin familia existen en este sistema de clasificación especies solitarias que no pertenecen a ningún grupo. Del mismo modo que en la sociedad existen individuos excluidos por ser sospechosos de ser brujos, en este sistema de clasificación existen especies no consideradas parte de una familia y a las que se atribuye ser brujas. Tal es el caso de ciertas especies de abejas. De este modo las diferentes formas de asociación y de exclusión en la sociedad ashaninka constituyen el modelo en este sistema para clasificar a los seres de la naturaleza.

Asimismo, hemos podido ver en este primer acercamiento al tema, que en la construcción de las relaciones entre la sociedad de los hombres y los animales juega un papel importante en el caso ashaninka la figura del padre o dueño de los animales. Partiendo de la figura mítica de los dueños o padres de los animales es atribuido al campo de las relaciones entre los seres de cultura o personas y los seres de natura o animales el carácter de una relación de donación de estos últimos a los primeros. Esta concepción es extendida a la función atribuida a ciertos mamíferos y aves como portadores y mensajeros en la entrega por las divinidades de ciertos recursos animales comestibles (larvas, peces). Forma parte de este conjunto de representaciones por medio de las cuales se construyen las relaciones entre hombres y animales la concepción que atribuye a ciertos seres vivientes la capacidad de la transformación interespecífica. Un ejemplo de ello es la idea de una transformación de ciertas personas, tras la muerte, en animales peyari que pueden devenir, en algunos casos, en guardianes de la especie.

Un último punto relevante que quisiéramos subrayar, es el de la relación entre los sistemas de clasificación aquí mostrados y los cambios en las relaciones de la sociedad ashaninka con el entorno natural. La relación de los ashaninka con su entorno natural ha experimentado cambios debido a su relación con la sociedad nacional y un aspecto importante de estos constituye la introducción de nuevas especies animales dirigida a la transformación del ecotipo indígena en la idea de volverlos más sedentarios. Como hemos podido ver en un caso, el de la abeja mielífera (Apis mellifera), esta fue incorporada en la clasificación indígena a través de la generación del taxón nerontoki como la especie prototípica de las abejas autóctonas. Vemos en este caso, que una nueva especie es incorporada al sistema preexistente a través de la generación de un nuevo taxón. De otra parte, animales domésticos como gallinas, patos domésticos, cerdos y 
carneros son incorporados a una categoría preexistente que con anterioridad designaba con el término wirantsi a aves y mamíferos capturados en etapas tempranas de su desarrollo y criados alrededor de la casa hasta el momento de su utilización para la alimentación. Así, vemos que en este caso, el contenido de una categoría es cambiado para incorporar las especies foráneas introducidas. Estos dos casos muestran que el sistema de clasificación discutido no es estático sino que ha incorporado los cambios sufridos por la sociedad ashaninka en sus relaciones con el entorno natural.

\section{Referencias citadas}

DESCOLA, P., 1996 - Constructing natures. Simbolic ecology and social practice. In: Nature and Societies. Anthropological perspectives; London and New York: Routledge.

DESCOLA, P., 2001 - Leçon inaugurale faite le Jeudi 29 mars 2001, Chaire d'anthropologie de la nature, Collège de France, 35p.; Paris: Collège de France.

DIXON, J. R. \& SOINI, P., 1986 - The Reptiles of the Upper Amazon Basin, Iquitos Region, Peru, 148p.; Milwaukee: Milwaukee Public Museum. .

DUELLMAN, W. E., 1978 - The Biology of an Equatorial Herpetofauna in Amazonian Ecuador, 300p.; The University of Kansas, Museum of Natural History, Miscellaneous Publication $\mathrm{N}^{\circ} 65$,

ELICK, J., 1969 - An ethnography of the Pichis valley Campas of Eastern Peru, PH.D. Dissertation, University of California, Los Angeles, microfilm.

EMMONS, L. H., 1997 - Neotropical Rainforest Mammals. A field Guide, 307p.; Chicago: The University of Chicago Press.

FJELDSA, J. \& KRABBE, N., 1990 - Birds of the High Andes. A manual to the Birds of the Temperate Zone of the Andes and Patagonia, South America, 890p.; Denmark:Zoological Museum University of Copenhagen and Apollo Books, Svendborg.

HILTY, S. L. \& BROWN, W. L., 1986 - A Guide to The Birds of Colombia, 836p.; Princeton: Princeton University Press.

KINDBERG, L., 1980 - Diccionario ashaninka. Yarinacocha, 466p.; Instituto Lingüístico de Verano.

LEVI-STRAUSS, C., 1966 - Du miel aux cendres, 450p.; Paris: Plon.

PETERS, J. \& OREJAS-MIRANDA, B., 1970 - Catalogue of the Neotropical Squamata. Part 1, 200p.; Washington: Smithsonian Institution Press Shakes. United States National Museum Bulletin 297.

ROJAS ZOLEZZI, E., 1994 - Los Ashaninka, un pueblo tras el bosque. Contribución a la etnología de los Campa ashaninka de la selva central peruana, 360p.; Lima: PUCP.

VIVEIROS DE CASTRO, E., 1998 - Cosmological deixis and amerindian perspectivism. The Journal of the Royal Anthropological Institute. Vol. 4, No 3: 469-488.

WEISS, G., 1975 - Campa Cosmology. Vol 52, Part 5, 300p.; New York: Anthropological Papers of the American Museum of Natural History.

WESKE, J. S., 1972 - The Distribution of the Avifauna in the Apurimac Valley of Peru with Respect to Environmental Gradients, Habitat, and Related species. Ph.D. Thesis, University of Oklahoma Graduate College, 325p. 


\section{APÉNDICE 1 \\ Clasificación ashaninKa de la Fauna según el MOdelo PROTOTÍPICO}

\section{Mamíferos}

La clasificación ashaninka de mamíferos señala como dirigente o prototípico de todos ellos a la danta o tapir kemari (Tapirus terrestris) por ser considerado el más grande. Asimismo, algunos informantes reúnen a esta misma especie en lo que vendría a ser una familia constituída por los mamíferos de mayor tamaño, a saber el sajino shintori o kitairiki (Tayassu tajacu), el venado maniro (el rojo Mazama americana y el gris Mazama gouazoubira), el ronsoco iweto (Hidrochaeris hidrochaeris) y la huangana pirachi (Tayassu peccari).

Siendo el principal criterio el de semejanza morfológica para el agrupamiento familiar, debemos señalar que para el caso de los mamíferos también existen otros criterios como el tipo de habitat (terrestre o arbóreo), horas de vigilia (diurnos o nocturnos) y la forma de locomoción. Así tenemos por ejemplo que los ashaninka reúnen en una sola familia a los animales nocturnos que viven en los árboles. Esta familia es liderada por el kinkajú kitsani (Potosflavus) y está constituida por la chozna mochori (Bassaricyon spp), la zariguella kapajeri (Delphis marsupialis) llamada también sari, el mono musmuqui pitoni (aotus sp.), el puerco espín tontori (Coendou bicolor), la laucha chiowante (Marmosa murina) y la rata de bambú tarato (Dactylomys dactylinus). Este último mamífero, la rata de bambú tarato, a pesar de su gran similitud morfológica con los demás roedores es excluido de la familia constituida por el ratón onkicha y el conejo de monte kima (Sylvilagus brasiliensis) porque mientras estos caminan por el suelo el otro vive trepado en el bambú y árboles pequeños y porque mientras estos son diurnos la rata de bambú tarato es nocturna.

Otra familia constituida por criterios que van más allá de lo morfológico es la liderada por el perezoso soroni (Choloepus hoffmanni) y constituida por el oso hormiguero wantana (Tamandua tetradactyla) y el oso hormiguero shani (Myrmecophaga tridactyla). En este caso estas especies son reunidas según el criterio de que viven en los árboles, poseen grandes uñas y cola prensil.

La siguiente familia está formada por los armadillos etini (Dasypus kappleri), kintero (Priodontes maximus), shinkipirótaki (Cabassous unicinctus) y kiripenaki (Dasypus novemcinctus) que constituyen una familia de la que kintero es el líder por ser el más grande del grupo.

Otra familia es aquella constituida por el conjunto de los monos reunidos alrededor del dirigente pinkatsari koshiri (Cebus albifrons) y compuesta por chiyeri (Saimirisciureus), osheto (Ateles paniscus), el mono aullador keniri(Alouatta seniculus) pitoni (Aotus sp) el mono choro komainaro o tsowero (Lagothrrix lagothricha) shiyeri (Cabuella pygmaea) chipi (Saguinus fuscicollis) y el tamarin heroni (Saguinus imperator).

El humairo oati (Eira barbara) es el líder de la familia que constituye junto con el achuni kapeshi (Nasua nasua), el pequeño perro negro de monte komero de cola de 
largos pelos que llegan hasta el suelo (Atelocynus microtis), el perro de monte otsitiniro llamado también oatiniro de pelaje amarillo y cola corta (Speothos venaticus) y el perro doméstico otsiti. Los ashaninka dicen que el komero se distingue por su pelaje negro y su cola de largos pelos y que si es atrapado puede llegar a ser domesticado mientras que el otsitiniro no. Sin embargo no por eso deja de ser komero para pasar a la categoría de otsiti pues el otsiti es considerado como un animal que viene de fuera.

El majaz samani (Agouti paca) lidera una familia constituida además por el añuje menor shatoni (Myoprocta pratti) y el añuje o cutpe sharoni (Dasyprocta variegata).

La nutria charawapana (Lontra longicaudis) lidera una familia compuesta por ella y la nutria parari (Mustela africana).

La ardilla roja meiri (Sciurus spadiceus) lidera la familia que constituye junto con el kotsero (Caluromys Lanatus) y la ardilla gris patyankori (Microsciurus flaviventer).

Finalmente los grandes felinos como el jaguar maniti (Panthera onca) y el matsontsori (Leopardus pardalis y Leopardus wiedii) forman una misma familia siendo el primero el líder. El maniti toma el nombre de kashékari cuando ha devorado a un hombre.

El murciélago pihiri (Orden Chiroptera) aunque esta categoría por sí sola involucra a todo un conjunto bastante extenso de murciélagos tanto los vampiros como los frugívoros como hemos visto en la clasificación general de los seres vivientes asháninka es reunido con la raya inaro en una misma categoría de anómalos del aire y el agua.

Dentro de los mamíferos, como hemos señalado queda como el gran solitario o "sin familia" el oso de anteojos maini (Tremarctos ornatus) por las características morfológicas que lo hacen tan distinto a todos los otros mamíferos de la región.

\section{Aves}

En la zona del río Ene existen según Weske (1972) alrededor de 600 aves de diferentes especies. Entre estas hemos podido determinar las siguientes familias.

Entre las aves el gran solitario es el paujil thamiri o tsamiri (Crax mitu) el que, como hemos señalado, dadas sus características morfológicas distintas a las otras aves de la región, no ha sido incorporada a los conjuntos de aves organizadas según en criterio de la similitud.

Los paujiles y perdices conforman una sola familia liderada por el paujil kentsori (Tinamous Tao) y de la cual forman parte onkiri (Tinamous Major), panawa (Crypturellus atrocallipus) el patsiri llamado también pachiri (Crypturellus tataupa), kontona (Odontophorus gujanensis), chiowero (Crypturellus obsoletus) y shirinti (Crypturellus soui).

Las chachalacas son agrupadas en una familia liderada por chioni (Aburria aburri) y constituida por sankati (Penélope jacquacu), marati (Penélope montagnii), kanari (Pipile cumanensis) etita (no identificada) y kiori (no identificada).

Las palomas son agrupadas en una familia liderada por el prototípico sampakitsi (Columba Cayennensis) y constituida por potooti (Columba speciosa), pamoro (Columba fasciata), kontsaro (Leptotila verreauxi y Leptotila rufaxila), tookiti (Claravis pretiosa y Claravis mondetoura) y pochoñeihi (Geotrygon montana). 
Los patos constituyen una familia definida. El pato marron con gris, el de cuello azulado y el de cuello rojo (Oxyura jamaicensis, Mergane aarmata y Anas flavirostris) son denominados igualmente pantyoni y lideran esta familia. Forma también parte de esta familia katari (Cairina moschata).

Los guacamayos y pericos constituyen una misma familia liderada por sawaro (Ara macao). Esta está constituida por kasanto (Ara ararauna, segun Weiss Ara Caninde), kimaro (Ara chloroptera) meanto (Ara militaris), saweto (Aratinga leucopthalmus), santero (Aratinga weddelli) y pareto (Bolborhynchus orbignesius y Bolborhynchus lineola). Sin embargo al interior de esta familia se define un subgrupo liderado por kintaro (Amazona farinosa) y constituido por erooti (Amazona ochrocephala), chorito (Pionus menstruus según Weiss), tyoríkiti (Hapalopsittaca melanotis), chokío (Forpus xanthopterygius), memeri (Pyrrhura picta) y teroori (Amazona mercenaria).

Los tucanes forman una familia liderada por opempe (Ramphastos cuvieri ya identificado por Weiss) y constituida por pishiro (Pteroglosus castanotis según Weiss), kaonkari (Aulacorhynchus coeruleicinctis), pishiti(Pteroglossus aff. torquatus) kitepari (Pteroglossus mariae), kechinti (Pteroglossus beauharnaesii), charini (Ramphastos aff. swainsonii) y awenti (no identificado).

Las golondrinas son lideradas por ashiwanti (Chaetura sp. y Panyptila Cayennensis) y forman parte de esta familia etsoni (Cypseloides rutilus y Atticora fasciata) y choríkiti (Neochelidon tibialis griseiventris) y pamachari (no identificada).

Los colibris forman una familia liderada por kaméwira (Florisuga mellivora) y se dividen en dos subfamilias: los tsonkiri de picos rectos y que vuelan alto al que pertenece el ya señalado prototípico (Amazilia lactea, Amazilia Chionogaster, Colibrí thalassinus, Colibri coruscans, Doryfera ludovicae, Lophornis delattrei, Chlorostilbon mellisugus, Hylocharis cyanna, Amazilia chienegaster, Amazilia lactea, Adelomyia melanogenys, Heliodoxa rubinoides, Heliodoxa leadbonteri, Heliodoxa branichii, Coeligena coeligena, Coeligena torquata, Coeligena violifer) y los wiisanti de picos curvos y que vuelan más bajo (Phaethornis guy, Phaethornis superciliosus, Phaethornis hispidus, Phaethornis stuarti Glaucis hirsuta).

Los pájaros carpinteros liderados por el prototípico tsikonte (phloeoceastes melanoleucus) forman una familia compuesta por chikonti (Dryocopus lineatus), toronti (no identificado) soapeti (Piculus leucolaemus), kiriheti (Piculus rubiginosus), motyókiri (veniliornis dignus) y tyohékiti (veniliornis nigriceps).

En el caso de los woodcrepers la lengua ashaninka reúne bajo el término chowáwate a las especies Dendrocolaptes certhia y Dendrocolaptes picumnus.

Los barbets constituyen una familia liderada por kentyokiriti (Capito niger) y constituida por pitororoti (no identificada)

Los cucos forman una familia dirigida por chiwani (Piaya cayana y Piaya minuta) y constituida por machomwroti (Dromococcyx phasianellus). Otros cucos que no forman parte de esta familia y que no forman parte de ninguna son keshito (Cyanocorax yncas) kootsatsati (no identificado) y sashinti (no identificado). 
Las garzas conforman una familia liderada por chiwini (Tigrisoma fasciatum) y constituida por sahanti (Butorides striatus), chompari (Casmerodius albus), kachoncho (ardea cocoi) pitiiri (Florida caerulea) y aawo (Egretta thula). Es necesario señalar que no nos fue posible determinar el nombre ashaninka del Mesembrinibis Cayennensis de color verdoso señalada por Weske como habitante del valle del Ene.

Los rapaces y carroñeros constituyen una familia liderada por el gallinazo tisoni (Daptrius ater) y conformada por shíronti (Buteo magnirostris) y makáwari (Leucopternis albicollis), shiiri (Ictinia plumbea), chotari (Micrastur ruficollis), séniro (Milvago chimachima), y méronti (Buteo albigula).

Buhos y lechuzas constituyen una familia liderada por el buho mamaro (Ciccaba virgata) y constituida por semito (Pulsatrix perspicilata), tontókoti (Otus albogularis), pompori (Otus watsonii) y sororonti (no identificado). Debemos señalar que Weske registra la presencia de 10 especies diferentes de buhos y lechuzas y es posible que estas denominaciones comprendan más de una especie.

Los chotacabras constituyen una familia liderada por mahoti (Nyctibius griseus) y constituida por narani (no identificada), ariti (no identificada) y santani (no identificada).

Pucacungas y pavas son agrupadas en una familia liderada por chioni (Aburria aburri) y constituida por sankati (Penélope jacquacu y Penélope montagnii), kanari (Pipile cumanensis) y etita (Ortalis guttata).

Los rállidos (rails) son agrupados en una familia liderada por koatsere (Aramides cajanea) y constituida por towinti (no identificado) peerereti (Aramides, Rallus nigricans) y yonkewa (no identificado)

Los hormigueros (antshrikes) constituyen una familia liderada por marini (thamnophilus doliatus) y constituida por tsontsomarati (Taraba major).

Las oropéndolas y casiques forman otra familia que está constituida por tsoori (Psarocolius decumanus y Psarocolius angustifrons) en posición de líder prototípico, konti (Scaphidura oryzivora), chiroti (denominación que comprende dos pequeñas aves muy similares de colores amarillo con negro Cacicus leucoramphus y Cacicus c. cela), mankori (Cacicus uropygialis) y shintípiro (Tachyphonus rufus).

Otra familia está constituida por golondrinas y vencejos. Liderada por la golondrina ashiwanti (Chaelatura sp. Paniptila Cayennensis) que ocupa la posición de líder prototípico, forman_parte de esta etsoni (Atticorafasciata) y choríkiti (Neochelidon tibialis griseiventris). Es necesario señalar que etsoni y choríkiti son considerados dentro de la categoría de pequeñas aves generalmente de brillantes colores llamadas tsimeri pero no así la prototípica ashivante.

El grupo de las pequeñas aves de brillantes colores denominadas tsimeri comprende un conjunto bastante diverso. Al interior de este conjunto tenemos también familias definidas, cada una liderada por una especie prototípica declarada dirigente o pinkatsari.

Es importante subrayar que las familias de aves definidas por los ashaninka corresponden generalmente a las familias definidas por los zoólogos. Sin embargo hay casos como los de la familia de las perdices, la familia de los halcones, milanos y 
caracaras y la familia de las oropéndolas y caciques en que se dan miembros de más de una familia. Incluso en un caso dentro de la familia de las golondrinas y del vencejo tenemos bajo una misma denominación, etsoni, a dos especies de dos familias distintas.

Otro aspecto a resaltar en el sistema de clasificación de aves ashaninka es el caso de la relación entre la subfamilia de los colibris tsonkiri y el ave tsonkiriniro(Chlorophanes spiza) que forma parte de la familia liderada por pichókiti. La denominación de esta ave sigue el patrón de clasificación que ya hemos visto para el caso de la relación entre el camarón kito y el alacrán kitoniro según el cual ciertos animales tienen su homólogo peligroso o dañino o -niro.

\section{Anfibios}

Los ashaninka reconocen como un grupo distinto de animales a los anfibios utilizando como término genérico el de masero que corresponde al sapo Bufo marinus.

Como al resto de los animales, los ashaninka clasifican los batracios en familias definidas compuestas por especies consideradas emparentadas entre sí y organizadas alrededor de una especie prototípica. Como en los casos anteriormente vistos, la especie prototípica es considerada dirigente o pinkatsari y las especies agrupadas a su alrededor sus parientes o ashaninka. En este caso tenemos dos familias definidas y tres especies consideradas sin familia o solitarias.

La primera familia esta constituida por dos variedades: el sapo denominado sowaito (Ischnocnema quixensis) que ocupa la posición de líder o prototípica y el owanto (Hyla boans). Estas especies son consideradas comestibles.

La segunda familia es organizada alrededor del sapo pirinto (Leptodactylus knudseni) que ocupa la posición prototípica de dirigente pinkatsari, la que tiene como parientes o ashaninka a las especies painto (Leptodactylus rhodonotus), sekito o tsekito (Hyla aff. minuta), tsopinto (Leptodactylus griseigularis), chopeta (Phyllomedusa tarsius) e iyento (Phrynohyas venulosa). Forman parte de esta familia también los sapos llamados tentekto o tento, tarairikiti y pacho que no nos fue posible identificar. Todas las especies en esta familia son consideradas comestibles.

Al parecer el criterio de agrupación por familias es la semejanza de tamaño entre las especies, siendo la primera de este la de los más grandes y la segunda la de los sapos menores de $5 \mathrm{~cm}$.

Además de las especies reunidas en familias, los ashaninka consideran como solitarios, "sin familia" al sapo no comestible owaratanta que no nos fue posible identificar. Según nuestros informantes este sapo que habita en las partes altas acostumbra introducirse en las fogatas, atraída por la luz del fuego. En base a esta característica del comportamiento de este animal, los ashaninka han construido un mito según el cual esta especie roba el fuego a los hombres introduciéndose brasas de la fogata por la cloaca. Asimismo se dice que es peligroso para los hombres, ya que cuando una persona se burla de su canto nocturno, aquel se transforma en un ser con aspecto humano provisto de un gran pene con el cual viola a los hombres ashaninka vengándose así de ellos.

Otras especies a las que no se les ha identificado familia son ooti (Leptodactylus pentadactylus) y chawerenchakiti (Osteocephalus leprieurii). Otras variedades 
reconocidas por los ashaninka son karakaratzi, paapato (Kindberg, 1980: 434) paapatzi, hoontzi y karawa (Rojas, 1994) pero no han podido ser identificadas.

A pesar de las limitaciones en la identificación de los sapos, en base a los casos reunidos por los ashaninka en la segunda familia podemos decir que al igual que para mamíferos, aves y peces el modo de clasificación de los batracios por los ashaninka es de tipo prototípico.

\section{Reptiles}

\section{Sauria}

Los ashaninka reconocen a las lagartijas como un grupo distinto de animales aun cuando no poseen un término general para referirse al conjunto. Al interior de este reconocen cuatro tipos distintos de lagartijas, a saber la llamada makota (Stenocercus roseiventris), chirimpi (no identificada), la karecha (Iphisa elegans), el shankoro (Kentrophyx altamazonica). Este es el único caso en que no existe una especie prototípica dentro de un grupo en la taxonomia ashaninka. Asimismo identifican a una iguana llamada makota que habita en las partes altas.

\section{Serpientes}

La clasificación ashaninka de ofidios agrupa estos animales en cuatro familias de especies consideradas emparentadas o ashaninka cada una con su dirigente o pinkatsari, posición ocupada por la especie considerada prototípica. Estas familias son definidas según el criterio de grado de peligrosidad. Así una primera familia está constituida por aquellas especies que no poseen veneno y no pican; la segunda está constituida por las que no tienen veneno pero pican cuando se las molesta; la tercera por aquellas que tienen veneno pero pican sólo cuando se las molesta; la cuarta y ultima familia está constituida por aquellas agresivas (con o sin veneno) que atacan al hombre sin que se las moleste.

Dentro de la familia de los no peligrosos tenemos en la posición de prototípico o dirigente a la serpiente kanarinke (Imantodes cenchoa cenchoa) de cuerpo aplastado piel crema y manchas alternadas marrón oscuro, siendo agrupados a su alrededor el tsoorinke (Drymobius rhombifer) de color gris con marrón, el shankoronke (Oxybelis argenteus), el shiaronki (Leptophis ahaetulla nigromarginatus) de color verde brillante y el kamatonke denominación otorgada a la especie Chironius scurrulus (verde oscuro a negra). Al interior de esta familia se define como la familia de las serpientes que pican aunque sin veneno cuando son molestados el constituido por kanarinke, siempre en posición prototípica y shankionkiehi, denominación otorgada a Dispas catesbyi (a manchas marrón oscuro rodeadas de blanco).

La familia de las serpientes venenosas que atacan cuando son molestadas está constituida por la cascabel koshipirinke (Crotalus durissus) de piel marrón claro con manchas negras y dibujos geométricos en amarillo que ocupa la posición del dirigente prototípico de la familia, a cuyo alrededor son agrupados como sus parientes o ashaninka la serpiente karaapariki (Helicops angulatus) de manchas marrón oscuro a lo largo del cuerpo y la jergón tawato (Bothrops atrox) de cuerpo marrón con manchas negras y anillos amarillos. 
Finalmente, en la familia de las serpientes más agresivas que atacan al hombre tenemos en la posición de dirigente o prototípica a la serpiente acuática anaconda mapichiri (Eunectes murinus) de color marrón-verde oliva con pequeñas manchas negras y amarillas acompañada de su pariente o ashaninka la shushupe kempiro (Lachesis muta muta) de color marrón claro y figuras geométricas romboides en negro y marrón.

Además de aquellas reunidas en familias tenemos como solitarias la mantona samporo (Boa constrictor constrictor) de manchas esféricas marrón claro rodeadas de color marrón oscuro, la boa esmeralda kintaronki (Corallus caninus) de color verde y manchas blancas y grises, la coral kiraaperoti (Micrurus spixii obscurus) de cuerpo con anillos rojos amarillos y negros y la serpiente kamahanire (Atractus major) de cuerpo de manchas marrones rodeadas de gris y dorso rojizo.

\section{Lagartos}

El único tipo de lagarto actualmente existente en la zona es el lagarto negro (Melanosuchus niger) denominado por los ashaninka saniri y considerado comestible.

\section{Tortugas}

En la zona del río Ene se encuentran la tortuga de tierra sempiti (Geochelone denticulata) llamada motelo en castellano regional y la tortuga de agua chótaro (Podocnemis unifilis) llamada regionalmente taricaya. Ambas constituyen una familia sin señalarse un prototípico.

\section{Peces}

La clasificación ashaninka de peces es construida a partir de dos criterios que se complementan. Un primer criterio es el de tamaño, de acuerdo al cual se define una categoría de peces pequeños, entre 02 y $10 \mathrm{~cm}$ como shiwa y que se distingue del resto de los peces más grandes. Un segundo criterio es el de la agrupación por familias según características morfológicas que hemos visto para los casos anteriores siguiendo el esquema de tipo prototípico agrupando alrededor de una determinada especie considerada el pinkatsari o dirigente a los ashaninka o parientes a la manera de un asentamiento ashaninka tradicional. Las familias así constituidas son siete. Ambos criterios se complementan como veremos.

El conjunto de los peces es denominado por los ashaninka shima, teniendo todo el conjunto de los peces como prototípico el pez que lleva este nombre que corresponde a la especie Prochilodus sp. conocida regionalmente como boquichico o chupadora. Al interior del conjunto de todos los peces, entendidos como shima se define de acuerdo al criterio de tamaño la familia de los más pequeños denominados shiwa. El prototípico de esta familia es el llamado mereto (Astyanax fasciatus) alrededor del cual son agrupadas las especies shimamiroki (Steindachnerina guentheri sp.), el kisoitokiri (Creagrutus sp.) y el shimpitaki (Astyanax maximus). Los miembros de dimensiones más pequeñas de esta familia son las especies Bryconamericus sp., Knodus sp. y 
Creagrutus sp. los que son denominados shiwahaniki, literalmente los shiwa más pequeños, y que constituyen en algunos casos como los de Knodus sp. y Creagrutus sp. especies que llegan a dimensiones mayores pero que se encuentran en sus primeras etapas de crecimiento.

La segunda familia en orden de tamaño de menor a mayor es la que corresponde en la clasificación científica a la familia Loricariidae que comprende las llamadas carachamas en castellano regional. La especie señalada como prototípica es en este caso el kempiti que es el miembro más grande de esta familia con $30 \mathrm{~cm}$ de largo [identificado por Weiss (1975) como Plecostomus sp. y por nosotros en base a especimen fotografiado como Hypostomus sp.]. Alrededor de esta especie señalada como el pinkathari o jefe del grupo de parientes son agrupadas shimpitaki (identificada por Weiss como Ancistrus sp. y por nosotros como Ancistrus tamboensis), kirishipiti o krishpi (Loricaria sp.), katantori (Plecostomus sp. según Weiss corroborado por nosotros), samoto (que por espécimen nosotros encontramos es el Hypostomus sp. habiendo sido identificado por Weiss anteriormente como Ancistrus sp.) y manatakiri (Ancistrus sp.). En esta familia nos encontramos además con el caso de la denominación hetari que a su vez denomina a dos especies claramente distinguidas: por una parte la denominada hetari kitetakiri [identificada por Weiss (1975) como Chaetostoma sp. y por nosotros como Chaetostoma lineopunctatum] y por otra la denominada hetari tsekinti [identificada por Weiss (1975) como Ancistrus sp.]. En el caso de esta familia, aun cuando el prototípico es kempiti que es señalado como el pinkatari o dirigente, el conjunto es denominado hetari. Weiss en la lista de peces recogidos por el señala otros nombres como metsonakiri (Plecostomus $s p$.). Nuestros informantes en el río Ene sin embargo señalaron no conocer esta denominación que probablemente corresponden a los ashaninka de otro río.

Las siguientes familias se definen claramente por el criterio de tamaño y comprenden miembros de diferentes familias distinguidas por los biólogos.

La siguiente familia se agrupa alrededor de chaupa (que Weiss identifica en base a fuentes secundarias como Syzlo como Curimatus elongatus y nosotros por especimen como Potamorhina sp. de la familia Curimatidae llamado yahuarachi en castellano regional) especie que ocupa en este grupo la posición de prototípico o dirigente pinkatsari. Son parte de esta familia kisoitokiri (Creagrutus sp.), chirinti (Synbranchus $s p$ ), kehikiriki (no identificado) y shintyoiroki o shintyoiriroki (no identificado).

La siguiente familia en tamaño es la agrupada alrededor de la figura del pez chenkori (Hoplias malabaricus identificado por Weiss y corroborado por nosotros) en posición de prototípico o dirigente pinkatsari. Sus ashaninka o parientes son las especies kipauri (Parodon sp.), chiroti (Leporinus arcus), korowiri (identificado por Weiss, 1975 como Characidium sp.), sosana (Crenicichla sp.) y kowana (Anostomidae, identificado por Weiss como Leporinus friderici). Forma parte de esta familia el pez llamado pahechi (no identificado).

Otra familia de peces es la liderada por el prototípico komairi llamado paco en castellano regional (identificado por Weiss siguiendo una fuente secundaria como Syzlo como Chalceus opalinus y por nosotros como un Cichlidae, Astronatus ocellatus por especimen). Miembros de esta familia son el sábalo mamori (identificado por Weiss como Brycon sp. y corroborado por nosotros), el paco o piraña komaro (Characidae, 
Serrasalmus sp.), la palometa chomenta (identificada por Weiss como Mylossoma sp. corroborado por nosotros), la corvina kowiri (identificada por Weiss como Salminus sp. y por nosotros como Astianax sp.), torooko (Curimatus cillata, Chio chio en castellano regional) y sonkarepenki (Curimata laticeps). Son también miembros de esta familia tsitsimentaki, chichita, shipetapari, chichipentaki, y ampontsi (no identificados).

El pez llamado por los ashaninka del Ene sonkarepenki (Curimata laticeps) forma parte de esta última familia y dado su significado cultural, su identificación requiere de una explicación especial. El nombre de este pez se encuentra asociado con el árbol Erithrina uley llamado sonkare en el Ene y con cuya floración su presencia numerosa es puesta en correlación. Se dice que cuando este árbol florece hacia la época central de la estación seca este pez llega surcando los ríos, el que se dice tiene la aleta caudal de un color rojizo de la misma tonalidad que las flores del árbol del que recibe su nombre. Su llegada anuncia la mijanada y el inicio de las grandes pescas con piscícidas y trampas en el río. En los ríos Perené y Tambo el árbol de flores rojas Erithrina uley recibe el nombre de tairi. En dichos ríos es puesto en correlación con un pez que recibe el nombre de tairipenki y que Weiss (1975) identificó como una variedad de Astyanax sp. o de Knodus sp. Así, se trata de diferentes peces pequeños que cumplen la misma función en el calendario de actividades de los ashaninka al ser puestos en relación con el árbol señalado.

Dentro de la familia liderada por mota en posición de prototípico (identificada por Weiss como Perugia sp.) encontramos como parientes ashaninka a shaori [identificada por Weiss (1975) como Rhamdia sp. y Narrorhamdia nemacheiri], kitotsakiri (identificada por Weiss como Pimelodus sp.), hanikiti (Pimelodidae, Pinirampus pirinampu), kitokiti (identificado por Weiss como Pimelodus sp. y por nosotros como Rhamdiaquelen de la familia Pimelodidae) ponke (Characidae, Knodus sp.), materi (Astroblepus sp.) y shewatarotsi [Pimelodidae, identificado por Weiss (1975) como Sorubim lima]. Forma también parte de esta familia kisontainari (no identificado).

Finalmente dentro de la familia de los más grandes liderada por el huacava omani en posición de prototípico [identificado por Weiss (1975) como Brachyplatystoma filamentosa] tenemos como parientes ashaninka al salton omani kitamarori (identificado por Weiss 1975 como Piratinga piraiba), la doncella iyochi (Pimelodidae identificado por Weiss como Pseudoplatystoma fasciatum), la doncella manitoichi (Pimelodidae, Pseudoplatystoma tigrinum), el turushuki toso (Oxydoras niger) ariti (Pseudopimelodus sp.), titiro [identificado por Weiss (1975) como Pimelodus Ornatus y por nosotros como un Pimelodidae, Rhamdia sp.]. Otros peces que forman parte de estafamilia pero que debido a su gran tamaño no nos fue posible colectar para identificación son sawirentsitaki, shaatonki, parentinato, metsotonkiri y los llamados saltones en castellano regional, moncho y charawa.

Además de los miembros de las familias de peces existen en la clasificación ashaninka peces a los que no les es atribuida la pertenencia a ninguna familia y que son considerados solitarios. Este es el caso del bagre con bigotes de ojos cubiertos de piel llamado suaro o maworo (Pseudocetopsis sp.). Tal es el caso también del tsewiro (Rhamphichtys Rostratus) y del pez en forma de delgada aguja llamado pityochichówaki (Pseudotylosurus microps). 
Otros animales acuáticos nombrados por los ashaninka son la raya inaro (Potamotrygonidae) que en la clasificación general es considerada familia del murciélago. No son considerados dentro de la categoría de shima ni la anguila tsinki (Sternarchidae, Adontosternarchus sp.) ni la raya inaro.

\section{Moluscos}

Respecto a los caracoles, los ashaninka consideran que estos constituyen una familia cuyo dirigente o pinkatsari es el Megalobulimus popelairianus (Nyst, 1845) denominado por ellos mapoto y que constituye el caracol de dimensiones más grandes en la zona comido a menudo por estos. El resto de la familia está constituida por el llamado terempinti [Aperostoma peruvianum (Da Costa, 1906)], el chowiwiñaki [Thaumastus bitaeniatus (Nyst, 1845)], el shankeónaki (Drymaeus aff. expansus), el sankiro (identificado por Weiss como Thaumastus melancheilus), el tsóiroki (Pomacea sp.) y el kontonanaki (Sultana sultana). Mapoto, terempinti y chowiwiñaki son especies terrestres y habitan en el suelo del bosque. El llamado chowiwinaki y el kontonanaki pasan buena parte de su vida en los árboles del bosque en donde se los puede encontrar a alturas considerables. El llamado tsóitoki es un caracol acuático comestible.

En la zona de los ríos Ene y Tambo existe el bivalvo sewáitiki (Diplodon sp.), considerado por los ashaninka comestible. No es considerado parte de ninguna otra agrupación.

\section{Planarias}

Las planarias llamadas penta (Orden Tremátode) que habitan en el agua de las quebradas acostumbran habitar también los estómagos de los animales domésticos y humanos por lo que los ashaninka llaman a dichos parásitos en general penta. Estos son distinguidos, sin embargo, de los gusanos intestinales de otro origen denominados shitsa.

\section{Lombrices}

Los ashaninka en general utilizan el término de imporoto para todas las lombrices redondas de tierra (Phylum Nemathelminthas).

\section{Antrópodos e Insectos}

Respecto a las arañas, los ashaninka designan al conjunto de estas con el nombre de heto y consideran a la tarántula, la especie considerada la dirigente o prototípica. Esta es llamada koshirihempeki, literalmente, araña mono.

Las mariposas son clasificadas en dos grandes grupos. Las coloridas mariposas diurnas son denominadas de manera general shaweta o santa. Las grises mariposas nocturnas de cuerpo grueso reciben el nombre genérico de matori. Los ashaninka no establecen ninguna distinción entre las diferentes especies de mariposas al interior de estos dos grandes grupos. Sin embargo, consideran como la pinkatsari o dirigente y que ocupa la posición prototípica a la mariposa denominada matzaranchi y que presenta la 
característica de ser crepuscular, es decir que sale al anochecer y al amanecer lo que la ubica en una posición intermediaria entre las diurnas y las nocturnas lo que explica su posición de prototípica en la clasificación. Esta característica fue remarcada por los ashaninka al hablar con mis informantes sobre esta mariposa. Esta mariposa, de alas celestes con marrón que es también la más grande en la zona es denominada en la clasificación científica Caligo Teucer Phorkys y es llamada vulgarmente mariposa buho debido a un gran círculo amarillo y negro en la parte posterior de cada una de las alas. Esta mariposa presenta 7 variedades distintas en la zona de la cordillera de Vilcabamba según el Dr. Gerardo Lamas del Museo de Historia Natural de Lima, pero los ashaninka no establecen diferencias de nombre entre dichas variedades. Sin embargo una mariposa similar, que a diferencia de la primera presenta varias figuras en forma de ojo de lechuza en cada ala (Morpho deidamia) y llamada también matzaranchi es considerada de mal agüero pues su presencia anuncia la llegada de enfermedades al hogar. Es distinguida también una mariposa de alas celeste claro metálico con borde negro (Morpho menelaus) a la que no se da un nombre particular siendo simplemente una shaweta y que como la anterior es también de mal agüero anunciando su ingreso a una casa la llegada de muertes y enfermedades. Durante nuestra estadía en el terreno pudimos observar en una ocasión cómo en medio de una reunión de bebida todos los invitados huyeron de la casa espantados cuando imprevistamente esta mariposa entró volando.

Si los ashaninka no distinguen a las diferentes mariposas — diurnas o nocturnascon nombres distintivos, en revancha utilizan diferentes nombres para nombrar a aquellas que en la forma inmadura de larva son utilizadas como recurso alimenticio. Así por ejemplo la larva inchapáriki (Familia Sphingidae), la larva erama (Familia Notodontidae), la larva tsiopa (Suborden Ditrysia), la larva inkórato (Familia Sphingidae), son formas inmaduras de mariposas diurnas y nocturnas. Las larvas de mariposa no comestibles son denominadas shaweta al igual que las mariposas adultas.

Es necesario señalar que las larvas comestibles de mariposa, a pesar de que los ashaninka son concientes de que son formas inmaduras de mariposa, son agrupadas en una misma familia junto con larvas igualmente comestibles de escarabajo. Este es el caso de las larvas llamadas sirikempi (Familia Cerambycidae), ameti (Familia Elateridae) y emoki (forma inmadura del escarabajo emótake Rhynchophorus palmarum) que siendo de escarabajo son reunidas con las ya señaladas de mariposa. Debemos señalar que en algunos casos larvas que nuestros informantes señalaron como de mariposas resultaron ser de escarabajos como fue el caso con la llamada sirikempi y en otros casos a la inversa, las supuestas larvas de escarabajo resultaron ser de mariposa como es el caso de inchapákiri.

El pinkatsari o prototípico de esta particular "familia" de larvas es denominada chirompe. Sin embargo sucede que en este caso esta denominación de chirompe comprende no una única especie sino a las larvas de varios escarabajos como es el caso del Acrocinus longimanus (L.) que en su forma madura recibe el nombre de chienchetaki, la larva del escarabajo llamado porootaki (Género Acanthoderes) y la larva del escarabajo llamado chakopitaki (Género Chalcolepidius). La característica común a estas larvas de escarabajo sería su gran tamaño en comparación con todas las otras, la cual es considerada por nuestros informantes el criterio para ser considerados prototípicos o jefes. 
Una larva que constituye una entidad independiente sin familia está constituida por el llamado maho (Orden Coleoptera, Familia Scarabaeidae), larva de escarabajo comestible de forma alargada y muchas patas que habita en pequeños túneles que excava en el suelo del bosque primario. Aparece en gran número a finales de la estación de lluvias en la zona de la confluencia de los ríos Ene y Perené a donde viajan los ashaninka de estos ríos para extraerlos con ayuda de largas puntas de flecha y alambres gruesos a los que han modelado a fuerza de golpes en forma de ganchos.

Otra larva que parece independiente y sin familia es la larva comestible de mosca llamada séchiki (Orden Díptera, Suborden Brachycera-Acalyptratae) que se desarrolla en los tallos podridos de la caña brava al borde de las quebradas.

Existen larvas acuáticas como el impita (Género Corydalus) con cabeza diferenciada del cuerpo y patas que habitan en las quebradas que no forman parte de la familia de larvas anteriormente mencionada.

Los escarabajos por sí mismos forman una familia cuyo prototípico es el escarabajo comestible llamado chienchétaki [Acrocinus longimanus (L.)] el de mayor tamaño en el grupo, de coraza con diseños negros rojos y amarillos, que habita en el árbol ojé y cuya larva forma parte del grupo denominado chirompe. Esta familia está compuesta por el escarabajo poorotaki (Familia Cerambycidae, SubFamilia Lamiinae, Género Acanthoderes) de color verde, que habita en el árbol lupuna blanca y cuyos huevos se transforman en uno de los gusanos del grupo denominado chirompe; el escarabajo emótake (Rhynchophorus palmarum) de color negro brillante con una larga trompa en la parte frontal, que se desarrolla en la palmera shapaja tsiyaro (Scheelea) y se transforma en la larva emoki ya mencionada; el escarabajo chakopitaki (Género Chalcolepidius) de color verdoso, que se impulsa a sí mismo dando saltos, que se desarrolla en la palmera shapaja donde pone una larva de las del conjunto comestible llamado chirompe; y el escarabajo comestible keshito (Familia Scarabaedae, SubFamilia Dynastinae) que se desarrolla en la caña brava.

Las hormigas constituyen una gran familia que tiene por pinkatsari o dirigente prototípico a la hormiga manihi [Paraponea clavata (Fabricius, 1775)]. Al interior de esta familia se definen sin embargo familias menores. Así, manihi hace familia con la hormiga katsarimoti (Camponotus Mayr, 1861) siendo la primera la líder de la familia. La hormiga eeni (Eciton rapax Fr. Smith, 1855) es la dirigente prototípica de una familia compuesta además por la hormiga meshikinti de color negro con puntos amarillos (subfamilia Ponerinae). Finalmente la hormiga sankori de color rojizo (Género Atta, Fabricius, 1804) es la dirigente y prototípica de una familia compuesta además por las hormigas katzarimoti (Género Camponotus, Mayr 1861), sechi (Género Camponotus Mayr, 1861) y shivókiro (Género Camponotus, Mayr 1861). Una familia más está constituida por las especies kantiriñoiriki y petáiriki, siendo la primera la dirigente prototípica pero no nos fue posible encontrar especímenes de estas para su identificación. Ciertamente hay otras especies reconocidas por los ashaninka no identificadas por nosotros. Es importante señalar que los ashaninka denominan kawiote a las hormigas aladas de las castas reproductoras de las diferentes especies.

Los saltamontes y grillos son denominados en general tsinari. Esta categoría tiene por prototípico o líder al saltamontes más grande de la zona denominado en 
ashaninka ankaro o tonkéronto de cerca de $20 \mathrm{~cm}$ de largo y de color verde identificado como Tropidacris latreilleri Perty. Al interior de esta gran familia los ashaninka distinguen dos familias diferentes, la de los charo constituida por los grillos o miembros de la familia Gryllotalpidae y la familia de los pitsiro constituida por los saltamontes o miembros de la familia Locustidae o Acrididae.

Abejas y avispas constituyen dos grupos bien diferenciados

Las abejas son denominadas neronto en general. La llamada nerontoki - la especie importada- [Apis mellifera (L.)], gran productora de miel es la prototípica de este grupo. Alrededor de ella son agrupadas como sus familiares tanto especies sociales que producen miel como la nativa peánire (Familia Apidae, Género Bombus) de gran tamaño y que construye sus panales bajo tierra en el bosque primario como especies no sociales que no producen miel como las solitarias abejas carpinteras llamadas pichi (Familia Anthophoridae, Subfamilia Xylocopine) y sanirontiki [Familia Anthophoridae Género Xylocopa (Neoxylocopa sp.)]. Estas últimas, las solitarias abejas carpinteras, constuyen sus nidos en los troncos secos de árboles muertos que perforan para este fin. No producen miel llevando néctar a sus larvas para alimentarlas. El macho es de color amarillo dorado y la hembra negra y en algunas especies esta se tornasola en verde o morado. La abeja carpintera sanirontiki es ubicada en el límite de la familia de las abejas con la familia de las avispas llamadas saní. De allí su nombre que podría ser traducido como abeja-avispa. Otras abejas son ubicadas al margen de esta familia siendo consideradas casos aislados y se les atribuye ser hechiceras matsi. Estas son la llamada shiriki (Familia Apidae, Subfamilia Meliponinae, Tribu Trigonini) y la tsetanti (Familia Apidae, Subfamilia Meliponinae, Tribu Trigonini, Género Partamona sp., Grupo Cupira). La primera vive bajo tierra en un pequeño túnel que excava y de esta se dice que trae a la gente enfermedades como el cólera y la fiebre ya que revolotea alrededor de las personas para obtener gotas de sudor siendo considerada un ser malevolente. La segunda se dice que acostumbra llevarse gotas de la sangre y pequeños trozos de la carne de los animales que son presa de los cazadores para comérselos y que con esto hace brujería contra estos últimos.

Las avispas son denominadas sani y el prototípico o dirigente pinkatsari es la especie denominada tamporo (Familia Vespidae, Género Polistes) que construye grandes panales de material apergaminado de forma cilíndrica semejante a un tambor (tamporo en idioma ashaninka) del cual deriva su nombre. En castellano regional estas avispas son llamadas avispas campana por la forma del nido o panal. Los ashaninka sin embargo distinguen dos familias de avispas, las grandes y las pequeñas siendo la prototípica de las pequeñas la especie denominada chonchoite (Género Polistes canadensis (L.) de nido de material apergaminado de $10 \mathrm{~cm}$ de largo) y líder de las grandes la ya mencionada tamporo (Género Polistes). Así tenemos alrededor de chonchoite, en la familia de las avispas pequeñas a las denominadas shipinkoki (Stelopolybia sp.), kahéreti (subfamilia Polybiinae, especie Stelopolybia sp. y Polibia sp.), tsota (Polistes versicolor (Oliver) y Polistes major Palisot de Beauvois) y chowichi (Mischocyttarus sp.). Alrededor de tamporo, la líder de las avispas grandes, tenemos a las denominadas tsirotisanine (Género Polistes) de panal de material apergaminado de 
$50 \mathrm{~cm}$ de largo, kosampi (Género Polistes) de panal apergaminado de $50 \mathrm{~cm}$ de altura, sanikitatakiri (Género Polistes) de panal de $60 \mathrm{~cm}$ de largo de material apergaminado, kipatsinari (Género Ammophilinae) que hace su nido excavando en el suelo, kewinti (Familia Sphecinae, Género Sphex) que anida haciendo un hueco en el suelo, a donde introduce los cuerpos de los insectos que caza, y las alfareras kowitsinari (Familia Sphécide, Subfamilia Sceliphronine) con panales de barro de forma esférica que semejan pequeñas ollas de barro que en ashaninka se denominan kowitsi y de donde deriva el nombre de esta especie. Las larvas de estas últimas son comestibles (1).

Las avispas en general dentro de las creencias ashaninka son consideradas kamari debido a que las picaduras de algunas especies pueden producir fiebres. Sin embargo, la gran excepción es la avispa kewinti que como hemos señalado anida en pequeños agujeros que excava en el suelo y en los que introduce los cuerpos de los insectos que caza de los cuales se alimenta. En ocasiones esta especie hace su nido en el piso de las casas junto a las paredes de cañas y entonces a menudo los ocupantes de esta pueden ver a esta avispa transportando por el aire de regreso a su nido las presas obtenidas en los exteriores cercanos lo que le da reputación de excelente cazadora. Cuando esta visitante se instala en la casa se dice que es de buen agüero ya que entonces el dueño de la casa tendrá una buena temporada de cacería.

Finalmente, los asháninka denominan a las diferentes especies de zancudo en general maño y entre los mosquitos distinguen a los itsito (no identificado), chito (no identificado), shineiki (no identificado), hooki o manta blanca y a un mosquito llamado aráwori que camina sobre el agua formando colonias en aguas con poca corriente en orillas de quebradas. Otros pequeños insectos voladores son llamados matori (Orden Homoptera, familia Derbidae), kachóneriki (no identificado), takinte (Orden Dermaptera) y periki (Orden Coleoptera, Familia Scolytidae conocidos como escarabajos de ambrosía y los orden Coleoptera, Familia Platypodidae).

(1) En América del Sur existen tanto avispas como abejas que construyen panales de arcilla en forma de vasijas. Es probable que para el caso de las llamadas kowitsinari los ashaninka involucren tanto abejas como avispas (Lévi-Strauss, 1966; 42 y ss.). Las limitaciones en nuestra recolección de muestras no nos ha permitido resolver este punto. 